\title{
Language Learning Strategies, Motivation and Gender in Foreign Language Context
}

\author{
Ranjeeva Ranjan 1,*, Andrew Philominraj \\ ${ }^{1}$ Department of Research and Graduate Studies, Universidad Católica del Maule, Chile \\ ${ }^{2}$ Faculty of Education, Universidad Católica del Maule, Chile \\ Received December 11, 2019; Revised December 24, 2019; Accepted January 16, 2020
}

Copyright $\bigcirc 2020$ by authors, all rights reserved. Authors agree that this article remains permanently open access under the terms of the Creative Commons Attribution License 4.0 International License

\begin{abstract}
The research in the field of language learning highlights two major paradigm shifts in the past few decades. First, the shift is from teacher-centered learning to learner-centered teaching and second related to learning processes through which learning occurs. In this second shift, research carried out in the field of language learning strategies (LLS) has amplified in the last few decades wherein the question of how the learners deal with their learning process by employing various kinds of learning strategies is being investigated systematically. This research article focuses on the profiles of learning strategies used by Indian students in learning Spanish as a foreign language, motivational orientations and gender aspect in using learning strategies. The participants $(\mathrm{N}=65)$ at two major universities teaching full-time Spanish courses at the undergraduate level were selected for the present research. It was found that the participants used social and metacognitive strategies the most and the memory strategies the least. The participants with interest in academic career chose to learn Spanish and the students with extrinsic motivation reported using learning strategy with higher frequency and there was no significant difference in the use of strategy concerning gender. In the end, conclusions are drawn and future area of research is suggested for researchers.
\end{abstract}

Keywords Motivation, Language Learning Strategies, Foreign Language; Metacognitive, Gender

\section{Introduction}

The process of learning a second/foreign language includes not only external factors but also psychological factors that play an important role. There is a paradigm shift in the function of the students who are perceived as active collaborators in the learning trajectory. There are several factors, which influence the learner and their learning process. One of the key concepts related to the learning progression is the language learning strategies (LLS) used by the learners in their learning process. There have been abundant research studies carried out on the important roles that strategies play in the learning of second or foreign language and these investigations have contributed immensely to our knowledge of their value in the learning process. One of the major challenges in this field refers to the notable variations in the linguistic achievements of students of a second or foreign language despite receiving similar amounts and qualities of exposure to the target language. Some language students seem to acquire more than others do. The research in the field of LLS started with this individual variation while learning with the appearance of the seminal article of J. Rubin [37] titled "What the "Good Language Learner" can teach us". In this seminal article, the individual disparity while learning and differential achievement among learners were examined. In the beginning, the research was more focused on reflecting the behaviors of "good language learners" and the characteristics, which were shared by the successful language learner [39]. In the 1990s, a series of research in the field of LLS $[23,24]$ helped it to gain much prominence in the field of second language acquisition and establishing itself as one of the major areas of second language research [39]. For some time this field was criticized during the beginning of this millennium but as Pawlak [31] rightly points out that the research in LLS has "never lost its appeal to practitioners, probably on account of the fact that the steps learners take to enhance their language learning are seen as tangible and amenable to pedagogical intervention."

Although there is a growing interest in this field of LLS and there is a lot of research on the relationship between the LLS use and motivation and gender in various context, there is no research in Indian language room context relating LLS use with motivation and gender. Since LLS use and motivation have been linked positively with the proficiency in various previous studies in different learning 
environments, examining the link between these elements would provide the practitioners and researchers with an understanding of the learning patterns and process better.

\subsection{LLS and Motivation: Theoretical Foundations}

Since its inception, an effort to define and classify them has always faced many criticisms. J. Rubin [37] referred strategies as "techniques or devices which a learner may use to acquire knowledge". For Oxford [24], LLS are "steps taken by the students to enhance their own learning". She adds that strategies are "especially important for language learning because they are tools for active, self-directed involvement, which is essential for developing communicative competence". O'Malley \& Chamot [23] refer to them as "the conscious thoughts and actions that learners take in order to achieve a learning goal. Strategic learners have metacognitive knowledge about their own thinking and learning approaches, a good understanding of what a task entails, and the ability to orchestrate the strategies that best meet both the task demands and their own learning strengths." Another very important aspect of the strategies is their conscious dimension. O'Malley \& Chamot [23] say that if a strategy is used so frequently, that it becomes automatic and unconscious, and then it is no longer a strategy, but should be referred to as a process, procedure or procedural skill. Therefore, consciousness is a fundamental element in the use of foreign language learning strategies. Cohen [3] also argues that the aspect of conscious choice is essential for the concept of language learning strategy because "the element of conscience is what distinguishes strategies from those processes that are not strategic." Oxford [26] in her recent book has taken a comprehensive approach and proposed an encompassing definition after content analyzing 33 definitions of learning strategies. She defined LLS as "complex, dynamic thoughts and actions, selected and used by learners with some degree of consciousness in specific contexts in order to regulate multiple aspects of themselves (such as cognitive, emotional, and social) for the purpose of (a) accomplishing language tasks; (b)improving language performance or use; and/or (c) enhancing long-term proficiency." She adds further "strategies are mentally guided but may also have physical and therefore observable manifestations. Learners often use strategies flexibly and creatively; combine them in various ways, such as strategy clusters or strategy chains; and orchestrate them to meet learning needs."

It is quite evident that the language students employ learning strategies consciously or unconsciously as they carry out a new task and cope with new information in a language classroom. The classroom offers a setting in which it is very probable that the learners find new information and meet difficult tasks. In this type of situation, they try to find the easiest and quickest manner to finish the task in the classroom. These efforts and enthusiasm to accomplish and finish the given tasks may be called strategies.

While style preferences and language strategies are important contributors to the acquisition of language skills, the degree of motivation is also important. Motivation is a psychological process that can be consciously promoted. This means that by using certain methods, it is possible to change students' motivation in a positive direction. For this reason, the skills to motivate students are an important aspect of any teacher's methodological repertoire. Gardner \& Lamberd [9] have recognized two types of motivation regarding second or foreign language learning: "integrative motivation and instrumental motivation". According to them, a student of the integrative orientation wants to learn a second/foreign language to chat, discover and perhaps transform into native speakers whom s/he admires and appreciates. Learners with instrumental orientation give little importance to the people who speak the target language, but their main aim is to learn the language for utilitarian reasons. A general belief about these two types of motivation is that integrative motivation is more significant than instrumental motivation as it involves an aspiration to integrate with a community that speaks the target language. A learner having instrumental motivation is expected to integrate and thus acquire the target language only to the point where s/he fulfilled her/his instrumental objectives. Dörnyei [4] has also praised the work in the field of motivation carried out by these two researchers. Another two concepts in this field are intrinsic and extrinsic which have to do with the source of motivation. The same has been produced below in a tabular form.

Table 1. Different Types of Motivation

\begin{tabular}{|c|c|c|}
\hline Motivation & $\begin{array}{c}\text { Integrative } \\
\text { orientation }\end{array}$ & Instrumental orientation \\
\hline Intrinsic & $\begin{array}{c}\text { Learner wants to } \\
\text { integrate with the } \\
\text { target culture (TC). }\end{array}$ & $\begin{array}{c}\text { Learner wants to achieve a } \\
\text { certain aim/objective. } \\
\text { (generally utilitarian } \\
\text { motive) }\end{array}$ \\
\hline Extrinsic & $\begin{array}{c}\text { Someone wants the } \\
\text { learner to integrate } \\
\text { with the TC. }\end{array}$ & $\begin{array}{c}\text { Someone wants the learner } \\
\text { to achieve aim/objective. } \\
\text { (generally utilitarian } \\
\text { motive) }\end{array}$ \\
\hline
\end{tabular}

Dörnyei [5] indicates that there exist a "second-language self-motivational system" inside the learner which describes a motivational landscape with three possibilities, one centered on the internal desires of the students, the second around the motivational regulations of social pressures exerted by significant or authorized persons in the environment of the students and the third around the real experience of being involved in the learning process. According to Dörnyei [5], the existence of any of these three systems is sufficient to provide the necessary influence of modulation and coordination in the direction to achieve knowledge of the second/foreign language. $\mathrm{He}$ adds that if all three systems are in harmony, that will have an increased cumulative effect. 


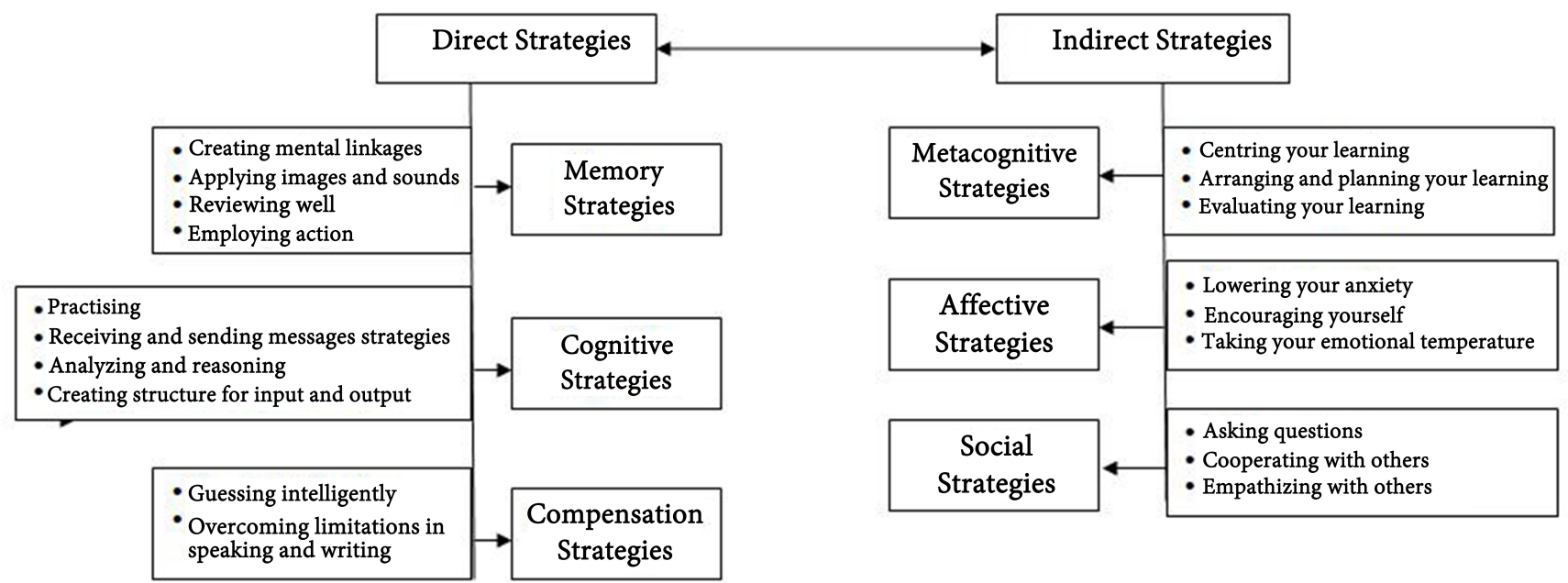

Figure 1. Classification of Language Learning Strategies [24]

\subsection{Classification of LLS}

One of the important challenges in this line of work is about the classifications of the strategies. The researchers have always confronted the problem of categorizing the strategies used by language learners. There are many reasons like the individual variation while learning as well as individual variables. The environmental factors also play an important role while classifying language learning strategies. Some of the most known classifications are those by Cohen [3], O’Malley \& Chamot [23], and Rubin [38]. The most accepted classification of strategies is that of Oxford. According to Takeuchi [39], Oxford [24] took the categorization effort a step further and proposed a comprehensive classification system. Hsiao \& Oxford [12] points out that "exactly how many strategies are available to students in second or foreign language learning and how these strategies should be classified is open to debate." Most of the attempts to classify the strategies more or less point towards the same categorization of language learning strategies without any fundamental changes. Oxford (1990) divides language-learning strategies into two main groups. The classification of strategies done by Oxford [24] is produced in the figure 1.

\subsection{Literature Review}

The field of LLS has expanded and many studies have been carried out in different languages and learning settings. They have provided us with interesting findings, which have many pedagogical implications. Along with finding the usage pattern of LLS, there have been many research studies to see and determine the relationship between the use of LLS and other learner variables like motivation, proficiency gender or year of study.

Concerning gender, research has consistently found that women outperform their male peers when it comes to language learning. According to Larsen-Freeman and Long
[16], female learners are often thought to be better learners than men. Oxford [23] suggests that "female students use significantly and frequently more learning strategies than their male counterparts." Numerous studies have discerned gender differences in the use of the language learning strategy in the context of English as a second language or foreign language $[7,27,28]$. One of the very first empirical research studies examining the role of gender in LLS usage was conducted by Politzer [35] who examined ninety undergraduate American students enrolled in Foreign language courses and found that female students used social/interactional strategies more often than their male learners. In another study regarding the gender difference in the usage of language learning strategies, Oxford and Nyikos [28] examined 1,200 US college students and found that females employed three strategy categories (formal practice, general study and input elicitation) more frequently than male counterparts. In another research at the University of Puerto Rico, Green and Oxford [27] informed that female learners used strategies significantly more often than male students. In another study in South Africa, Dreyer and Oxford [6] reported that, overall, females used strategies more often than males and that females employed social and metacognitive strategies more frequently. Peacock and Ho [32] in their study with 1,006 Chinese EFL learners (51\% male and $49 \%$ female) found that females had reported significantly higher use of all six categories on the Strategy Inventory for language learning (SILL) questionnaire than did males. Besides, they found that females used nine individual strategies with much higher frequency than males.

In most studies on this aspect, the results showed that women used second language or foreign language learning strategies significantly more often than men. However, there are some research studies, which have reported markedly different findings. Hashim and Sahil [11] in their study in Malaysia with 246 college students found that, 
apart from affective strategies, which women used more frequently, no difference was observed in the other SILL categories. Wharton [42], in research work with 678 university students in Singapore, reported that women employed a significantly less number of strategies than men. Griffith [10] in her research work in New Zealand with 348 students (114 males and 234 females) found no statistically significant difference in strategy use by gender. In another study at Sultan Qaboos University in Oman with 128 students (39 males and 89 females), Radwan [36] reported that there were no significant differences in the overall strategy use between male and female students and male students used slightly more memory, cognitive, and metacognitive strategies than female students in the SILL categories. In a more recent research study in Spain by on 206 Spanish students of English from different proficiency levels, Martínez et al. [18] reported that there were no statistically significant differences neither in overall use nor in any of the six categories between the LLS use of males and females.

Takeuchi et al. [40] inform that there is a consensus among researchers that more motivated learners tend to use a wider range of LLS more frequently. One area that requires more attention to know the causality i.e. whether motivation leads to LLS use or LLS use leads to the betterment of language proficiency, which in turn increases motivation. Martínez et al. [18] underline that "there is a reciprocal relationship between these two variables in the sense that motivation leads to strategy use and strategy use to motivation." Mochizuki [19] in a research study on 157 college students in Japan found that Asian university students used LLS more frequently than less motivated students in all six categories of SILL strategies. Wharton [42] also reported a similar result in a study on 678 university students in Singapore. In Taiwan, Peng [33] tried to see the relationship between the motivation to learn English as a foreign language and the learning strategy used by 32 students in a High School. Significant differences were found between the use of the strategy and each motivational aspect (i.e., motivational intensity, intrinsic motivation, extrinsic motivation and motivation of requirements). In another similar study in Taiwan, Liao [17] carried out a study to see the motivation to learn EFL and its relation to strategy usage. In this study, the motivation of the students to learn English was significantly correlated with their use of learning strategies.

\subsection{Research Questions}

In the present research work, the researchers have tried to see the overall pattern of the use of language learning strategies while learning Spanish as a foreign language (SFL) in India. In this research study, the general profiles of learning strategies employed by students of Indian universities who learn SFL are investigated to see which strategies they use most. The research questions that form the core of the present work about the use of the learning strategy in teaching and learning Spanish in Indian universities are detailed below:

A. Which type of language learning strategies do learners employ more frequently in the process of learning Spanish as a foreign language in India?

B. Which type of language learning strategies do learners employ less frequently in the process of learning Spanish as a foreign language in India?

C. Is there any relationship between gender and the use of language learning strategies? Which strategies do the female use more frequently and vice versa?

D. What is the principal motivation for learning Spanish in India and how is it related to the use of language learning strategies?

\section{Materials and Methods}

The present research is a quantitative cross-sectional study within the characteristics of the descriptive correlational framework. This work is a non-experimental type in which the self-reported learning strategies were examined with statistical and interpretive analysis.

\subsection{Participants and Research Instruments}

For the present study, 65 participants (undergraduate students of Spanish Degree course) were selected from two major central universities, i.e. Jawaharlal Nehru University (JNU) of New Delhi and English and Foreign Languages University (EFLU) of Hyderabad campus.

The details of the participants are presented below in the tabular form.

Table 2. Number of students who form part of the research study

\begin{tabular}{|c|c|c|c|}
\hline Year of study & $\begin{array}{c}\text { JNU } \\
\text { (New Delhi) }\end{array}$ & $\begin{array}{c}\text { EFLU } \\
\text { (Hyderabad) }\end{array}$ & Total \\
\hline First Year & 19 & $0^{*}$ & 19 \\
\hline Second Year & 10 & 5 & 15 \\
\hline Third Year & 17 & 14 & 31 \\
\hline Total & 46 & 19 & 65 \\
\hline
\end{tabular}

*There was no admission in the first year when this research study was carried out.

From the first year, there were $33.8 \%$, from the second $18.5 \%$ and from the third $47.7 \%$. Regarding the age of the participants, the minimum was 18 years and the maximum 27. In the current study, the researcher has used the questionnaire as the main instrument to collect the data. This questionnaire has the following parts:

Part 1: Individual background questionnaire (IBQ)

Part 2: SILL Questionnaire

Part3: Questionnaire regarding the reason for learning Spanish to reflect motivation

For this study, one of the popular quantitative tools, 
Strategy Inventory for Language Learning (SILL), is used. This is a questionnaire developed by Oxford in 1990 designed to assess LLS use. The participant has to think about each strategy and then answer them on a Likert scale of five. SILL consists of the following six parts.

A: Memory strategies (remembering) - 9 strategies

B: Cognitive strategies (mental processes) - 14 strategies

C: Compensation strategies (compensation) - 6 strategies

D: Metacognitive strategies (organization) - 9 strategies

E: Affective strategies (feelings, emotions) - 6 strategies

F: Social strategies (social learning with peers, natives) -6 strategies

The questionnaire regarding motivation was aimed at knowing the reason for learning this foreign language. The students were given a list of five options to choose for which they wanted to learn Spanish. There was also a space provided in case any students wanted to provide any other reason.

\subsection{Pilot Test}

To assess the feasibility and verify the effectiveness of the questionnaire, the questionnaire was given to ten third-year students at EFLU University, Hyderabad. This is done to reduce any unforeseen problems, detecting possible errors, the degree of complexity and understanding of the questionnaire.

\subsection{Data Collection Phase}

The questionnaire was given out in keeping with the practice summarized by Nyikos and Oxford [22]. The aim of the investigation was made clear to the participants. The questionnaire was distributed and the participants were asked to finish them during class time. The goal was aimed at getting students to reflect on their learning and to increase awareness of strategy options. The researcher was present during the survey at both the above-mentioned universities Ethics was maintained during the research process by asking for permission, assurance of confidentiality etc.

\section{Results}

After carrying out the survey, the data from the SILL questionnaires were collected and analyzed in Excel and SPSS using various statistical tools, such as t-test, ANOVA, Spearman's rho test, etc. to compare different results.

\subsection{Cronbach's Alpha}

The reliability of all questions in SILL questionnaire for all participants was very high $(\alpha=.89)$. The standard reliability score has been .70 [41] and in this case, it was more than the respectable range (Table 3 ).

Table 3. Cronbach's Alpha Test

\begin{tabular}{|c|c|c|}
\hline Cronbach's Alpha & Standardized Cronbach's alpha & Items \\
\hline 0.889 & 0.895 & 50 \\
\hline
\end{tabular}

\subsection{Overall Strategy Use}

The first two research questions of this investigative study were associated with finding the most and least frequently used strategies amongst the participants. For this purpose, the students' data were analyzed by using one-way analysis of variance (ANOVA). The result of ANOVA revealed significant differences $(\mathrm{F}=14.231, \mathrm{p}$ $=.000$ ) statistically in the overall use of LLS by all the participants of the present study. Table 4 illustrates the descriptive statistics together with the ranking based on the prioritization of LLS use as reported by the students. As apparent from Table 4, the participants reported using social strategies $(\mathrm{M}=3.62, \mathrm{SD}=.68)$ most frequently and memory strategies $(\mathrm{M}=2.85, \mathrm{SD}=.58)$ the least. From the same Table, it can be found that social and metacognitive strategies $(\mathrm{M}=3.60)$ are in higher usage category $(\mathrm{M}=3.5$ -5.0) [24]. The other categories of LLS fall into medium usage category $(\mathrm{M}=2.5-3.4)$. Compensatory strategies $(M=3.33)$, followed by cognitive strategies $(M=3.24)$ and affective strategies $(\mathrm{M}=2.98)$, and finally the least used category, memory strategies $(\mathrm{M}=2.85)$ fall in the medium usage group. Table 5 is the key given by Oxford [24] to categorize the usage of language learning strategies.

Table 4. Average use of six types of learning strategies

\begin{tabular}{|c|c|c|c|c|c|c|c|c|}
\hline Variable & Items & Mean & SD & Minimum & Maximum & Rank & F & Sig \\
\hline Memory & 9 & 2.85 & 0.58 & 1.44 & 4.00 & 6 & 14.231 & 0.00 \\
\hline Cognitive & 14 & 3.24 & 0.60 & 1.93 & 4.79 & 4 & & \\
\hline Compensation & 6 & 3.33 & 0.69 & 2.00 & 4.83 & 3 & & \\
\hline Metacognitive & 9 & 3.60 & 0.73 & 1.89 & 4.89 & 2 & & \\
\hline Affective & 6 & 2.98 & 0.65 & 1.67 & 4.50 & 5 & & \\
\hline Social & 6 & 3.62 & 0.68 & 2.33 & 5.00 & 1 & & \\
\hline Total & 50 & 3.27 & 0.71 & 1.44 & 5.00 & & & \\
\hline
\end{tabular}


Table 5. Strategy Usage Results profile key (Oxford, 1990)

\begin{tabular}{|c|l|c|}
\hline \multicolumn{2}{|c|}{ Strategy Usage Results Profile Key } & 4.5 to 5.0 \\
\hline \multirow{2}{*}{ High } & Always or almost always used & 3.5 to 4.4 \\
\cline { 2 - 3 } & Usually used & 2.5 to 3.4 \\
\hline \multirow{2}{*}{ Medium } & Sometimes used & 1.5 to 2.4 \\
\hline \multirow{2}{*}{ Low } & Generally not used & 1.0 to 1.4 \\
\cline { 2 - 3 } & Never or almost never used & \\
\hline
\end{tabular}

To find the multiple differences between the six different categories of learning strategies, a Scheffé post hoc test was conducted. Many significant differences between the different LLS categories were revealed by the multiple comparisons. Table 6 presents the Scheffé test results.

Table 6. Scheffé results for multiple comparisons among various strategy groups

\begin{tabular}{|c|c|c|c|c|c|c|}
\hline Strategy & Memory & Cognitive & Compensation & Metacognitive & Affective & Social \\
\hline Memory & & 0.060 & 0.007 & 0.000 & 0.957 & 0.000 \\
\hline Cognitive & & & 0.988 & 0.100 & 0.417 & 0.064 \\
\hline Compensation & & & & 0.412 & 0.109 & 0.300 \\
\hline Metacognitive & & & & & 0.000 & 1.000 \\
\hline Affective & & & & & & \\
\hline Social & & & & & & \\
\hline
\end{tabular}

\subsection{Item Wise Strategy Use}

Table 7 depicts the fifty SILL strategy items along with their mean values (in descending order from high to low used) for all the participants of the present study. The strategy item that was reported being used the most pertained to metacognitive category. The item was "I pay attention when someone is speaking Spanish" $(\mathrm{M}=4.16, \mathrm{SD}=.83)$. The strategy which was reportedly being used the least (and the only one that fell below the mean of 2) was from the category of memory, "I use flashcards to remember new Spanish words" ( $\mathrm{M}=1.95, \mathrm{SD}=1.12)$.

Among the top fifteen most used strategies which are in high usage range ( $M=3.50$ or above), there were five metacognitive, four social, three cognitive, two compensatory and one affective. There were no memory strategies in the higher usage category.

Table 7. Preference of language learning strategies by Spanish learners in India

\begin{tabular}{|c|c|c|c|c|c|c|c|c|}
\hline Sl & Language learning strategies & Type & M & SD & $\mathbf{F}$ & SD & Ma & SD \\
\hline & High usage ( $M=3.50$ or above) & & & & & & & \\
\hline 1 & I pay attention when someone is speaking Spanish. & Met & 4.16 & 0.83 & 4.22 & 0.76 & 4.08 & 0.96 \\
\hline 2 & I think about my progress in learning Spanish. & Met & 3.95 & 1.05 & 3.86 & 1.20 & 4.08 & 0.80 \\
\hline 3 & $\begin{array}{l}\text { If I can't think of a Spanish word, I use a word or phrase } \\
\text { that means the same thing. }\end{array}$ & Com & 3.92 & 1.19 & 3.81 & 1.21 & 4.08 & 1.16 \\
\hline 4 & I try to learn about the culture of Spanish speakers. & Soc & 3.82 & 1.22 & 3.86 & 1.10 & 3.77 & 1.39 \\
\hline 5 & I try to find out how to be a better learner of Spanish. & Met & 3.79 & 1.16 & 3.89 & 1.09 & 3.65 & 1.26 \\
\hline 6 & I ask questions in Spanish. & Soc & 3.79 & 0.98 & 3.64 & 1.02 & 4.00 & 0.89 \\
\hline 7 & $\begin{array}{l}\text { I notice my Spanish mistakes and use that information to } \\
\text { help me do better. }\end{array}$ & Met & 3.74 & 1.02 & 3.81 & 0.98 & 3.65 & 1.09 \\
\hline 8 & $\begin{array}{l}\text { If I do not understand something in Spanish, I ask the } \\
\text { other person to slow down or say it again. }\end{array}$ & Soc & 3.73 & 1.15 & 3.81 & 0.92 & 3.62 & 1.42 \\
\hline 9 & $\begin{array}{l}\text { I encourage myself to speak Spanish even when I am } \\
\text { afraid of making a mistake. }\end{array}$ & Aff & 3.69 & 1.20 & 3.78 & 1.15 & 3.58 & 1.27 \\
\hline 10 & To understand unfamiliar Spanish words, I make guesses. & Com & 3.65 & 1.19 & 3.72 & 0.94 & 3.54 & 1.48 \\
\hline 11 & $\begin{array}{l}\text { I first skim in a Spanish passage (read over the passage } \\
\text { quickly) then go back and read carefully. }\end{array}$ & $\operatorname{Cog}$ & 3.60 & 1.19 & 3.67 & 1.17 & 3.50 & 1.24 \\
\hline 12 & $\begin{array}{l}\text { I look for words in my own language that are similar to } \\
\text { new words in Spanish. }\end{array}$ & $\operatorname{Cog}$ & 3.56 & 1.18 & 3.56 & 1.03 & 3.58 & 1.39 \\
\hline 13 & I look for people I can talk to in Spanish. & Met & 3.56 & 1.15 & 3.53 & 1.11 & 3.62 & 1.24 \\
\hline
\end{tabular}




\begin{tabular}{|c|c|c|c|c|c|c|c|c|}
\hline 14 & I ask Spanish speakers to correct me when I talk. & Soc & 3.56 & 1.34 & 3.58 & 1.23 & 3.54 & 1.50 \\
\hline \multirow[t]{2}{*}{15} & I practice the sounds of Spanish. & $\operatorname{Cog}$ & 3.53 & 1.05 & 3.56 & 1.00 & 3.50 & 1.14 \\
\hline & Medium usage $(M=2.50-3.40)$ & & & & & & & \\
\hline 16 & I practice my Spanish with other students. & Soc & 3.48 & 0.99 & 3.42 & 0.84 & 3.58 & 1.17 \\
\hline 17 & $\begin{array}{l}\text { I think of the relationships between what I already know } \\
\text { and new things I learn in Spanish. }\end{array}$ & Mem & 3.44 & 1.20 & 3.44 & 1.16 & 3.42 & 1.27 \\
\hline 18 & I have clear goals for improving my Spanish skills. & Met & 3.42 & 1.09 & 3.56 & 1.05 & 3.23 & 1.14 \\
\hline 19 & I use the Spanish word I know in different ways. & $\operatorname{Cog}$ & 3.39 & 1.05 & 3.31 & 0.92 & 3.50 & 1.21 \\
\hline 20 & I try to talk like native Spanish speakers. & $\operatorname{Cog}$ & 3.37 & 1.32 & 3.53 & 1.30 & 3.15 & 1.35 \\
\hline 21 & I start conversations in Spanish. & $\operatorname{Cog}$ & 3.37 & 1.13 & 3.33 & 1.01 & 3.42 & 1.30 \\
\hline 22 & I try to find patterns in Spanish. & $\operatorname{Cog}$ & 3.37 & 1.31 & 3.22 & 1.31 & 3.58 & 1.30 \\
\hline 23 & I try to find as many ways as I can to use my Spanish. & Met & 3.34 & 1.12 & 3.31 & 1.12 & 3.38 & 1.13 \\
\hline 24 & I ask for help from Spanish speakers. & Soc & 3.34 & 1.27 & 3.28 & 1.14 & 3.42 & 1.45 \\
\hline 25 & $\begin{array}{l}\text { I watch Spanish language TV shows spoken in Spanish or } \\
\text { go to movies spoken in Spanish. }\end{array}$ & $\operatorname{Cog}$ & 3.26 & 1.27 & 3.25 & 1.23 & 3.27 & 1.34 \\
\hline 26 & $\begin{array}{l}\text { When I cannot think of a word during a conversation in } \\
\text { Spanish, I use gestures. }\end{array}$ & Com & 3.26 & 1.20 & 3.14 & 1.17 & 3.42 & 1.24 \\
\hline 27 & $\begin{array}{l}\text { I try to guess what the other person will say next in } \\
\text { Spanish. }\end{array}$ & Com & 3.26 & 1.27 & 3.19 & 1.24 & 3.35 & 1.32 \\
\hline 28 & $\begin{array}{l}\text { I find the meaning of a Spanish word by dividing it into } \\
\text { parts that I understand. }\end{array}$ & $\operatorname{Cog}$ & 3.24 & 1.25 & 3.19 & 1.12 & 3.31 & 1.44 \\
\hline 29 & $\begin{array}{l}\text { I connect the sound of a Spanish word and an image or } \\
\text { picture of the word to help me remember the word. }\end{array}$ & Mem & 3.23 & 1.17 & 3.00 & 1.12 & 3.54 & 1.17 \\
\hline 30 & $\begin{array}{l}\text { I remember a new Spanish word by making a mental } \\
\text { picture of a situation in which the word might be used. }\end{array}$ & Mem & 3.21 & 1.12 & 3.28 & 1.06 & 3.12 & 1.21 \\
\hline 31 & $\begin{array}{l}\text { I plan my schedule so I have enough time to study } \\
\text { Spanish. }\end{array}$ & Met & 3.19 & 1.20 & 3.28 & 1.20 & 3.12 & 1.22 \\
\hline 32 & $\begin{array}{l}\text { I look for opportunities to read as much as possible in } \\
\text { Spanish. }\end{array}$ & Met & 3.19 & 1.25 & 3.47 & 1.18 & 2.81 & 1.27 \\
\hline 33 & I try to relax whenever I feel afraid of using Spanish. & Aff & 3.19 & 1.27 & 3.22 & 1.27 & 3.15 & 1.29 \\
\hline 34 & $\begin{array}{l}\text { I use new Spanish words in a sentence so I can remember } \\
\text { them. }\end{array}$ & Mem & 3.13 & 1.09 & 3.11 & 1.14 & 3.15 & 1.05 \\
\hline 35 & I review Spanish lessons often. & Mem & 3.08 & 1.30 & 3.11 & 1.33 & 3.04 & 1.28 \\
\hline 36 & $\begin{array}{l}\text { I remember the new words or phrases by remembering } \\
\text { their location on the page, on the board, or on a street sign. }\end{array}$ & Mem & 3.03 & 1.45 & 3.25 & 1.36 & 2.73 & 1.54 \\
\hline 37 & $\begin{array}{l}\text { I make up new words if I do not know the right ones in } \\
\text { Spanish. }\end{array}$ & Com & 3.03 & 1.28 & 2.94 & 1.35 & 3.15 & 1.19 \\
\hline 38 & I try not to translate word-for-word. & $\operatorname{Cog}$ & 3.00 & 1.38 & 3.22 & 1.42 & 2.69 & 1.29 \\
\hline 39 & I read for pleasure in Spanish. & $\operatorname{Cog}$ & 2.97 & 1.35 & 3.17 & 1.32 & 2.69 & 1.38 \\
\hline 40 & I write notes, messages, letters, or reports in Spanish. & $\operatorname{Cog}$ & 2.90 & 1.40 & 3.25 & 1.34 & 2.42 & 1.36 \\
\hline 41 & $\begin{array}{l}\text { I talk to someone else about how I feel when I am learning } \\
\text { Spanish. }\end{array}$ & Aff & 2.90 & 1.36 & 2.81 & 1.43 & 3.04 & 1.28 \\
\hline 42 & I say or write new Spanish words several times. & $\operatorname{Cog}$ & 2.89 & 1.28 & 2.89 & 1.17 & 2.88 & 1.45 \\
\hline 43 & $\begin{array}{l}\text { I make summaries of information that I hear or read in } \\
\text { Spanish. }\end{array}$ & $\operatorname{Cog}$ & 2.89 & 1.36 & 2.78 & 1.35 & 3.04 & 1.37 \\
\hline 44 & I give myself a reward or treat when I do well in Spanish. & Aff & 2.89 & 1.47 & 2.78 & 1.55 & 3.04 & 1.37 \\
\hline 45 & I read Spanish without looking up every new word. & Com & 2.87 & 1.34 & 3.00 & 1.37 & 2.69 & 1.29 \\
\hline 46 & $\begin{array}{l}\text { I notice if I am tense or nervous when I am studying } \\
\text { Spanish. }\end{array}$ & Aff & 2.82 & 1.41 & 2.97 & 1.44 & 2.62 & 1.36 \\
\hline \multirow[t]{2}{*}{47} & I use rhymes to remember new Spanish words. & Mem & 2.56 & 1.53 & 2.50 & 1.58 & 2.65 & 1.50 \\
\hline & Low usage ( $M=2.40$ or below) & & & & & & & \\
\hline 48 & I write down my feelings in a language-learning diary. & Aff & 2.35 & 1.49 & 2.64 & 1.64 & 1.96 & 1.18 \\
\hline 49 & I physically act out new Spanish words. & Mem & 2.05 & 1.11 & 2.08 & 1.18 & 2.00 & 1.02 \\
\hline 50 & I use flashcards to remember new Spanish words. & Mem & 1.95 & 1.12 & 2.06 & 1.19 & 1.81 & 1.02 \\
\hline
\end{tabular}

Mem (Memory strategies), Cog (Cognitive strategies), Com (Compensation strategies), Met (Metacognitive strategies), Aff (Affective strategies), Soc (Social strategies). Ma (Male), F (Female) 
The data obtained from the questionnaire was changed into a categorical variable. First, the mean value for all strategy category was determined for every participant. Then, the strategy group with the highest mean value was presumed the participant's most frequently used type of strategy category. Based on this conversion, the data is presented and indicated in Figure 2. 29\% of the participants were found in Social strategies group, $27 \%$ in Metacognitive, $21 \%$ in Compensation, $15 \%$ of the participants had two equal highest mean scores for the strategy categories, 5\% in Cognitive and 3\% in Affective. Interestingly, no one reported using memory categories as the most important one in this group.

\subsection{Spearman's Rho Correlation}

Then the calculation of Spearman's Rho correlation was performed to investigate the relationship between the strategies' pairs. Spearman's Rho is a non-parametric test, which is used to quantify the strength of association between two variables. In this case, a positive correlation means that participants who get high scores in one strategy are expected to get high in the other strategy of the pair. Likewise, the participants scoring less in the previous strategy are expected to get low for the other strategy of the pair.

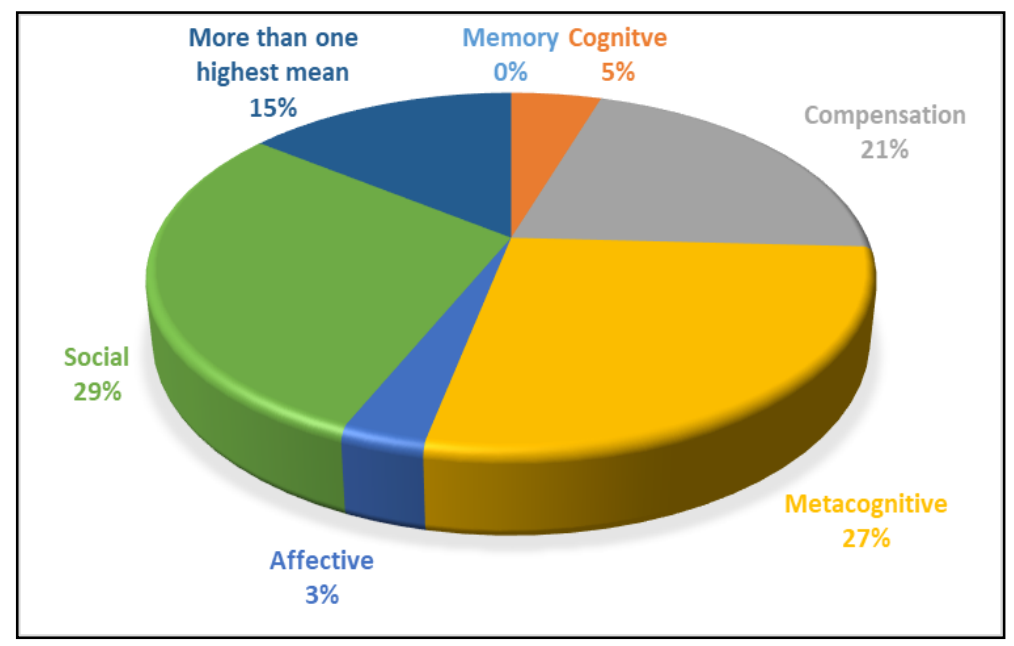

Figure 2. \% of participants according to their reported highest mean

Table 8. Result of Spearman's Rho Test

\begin{tabular}{|c|c|c|c|c|c|c|c|}
\hline \multicolumn{2}{|c|}{ Spearman's rho- Correlation } & \multirow{2}{*}{$\begin{array}{c}\text { Mem. } \\
1.000 \\
\end{array}$} & \multirow{2}{*}{$\begin{array}{c}\text { Cog. } \\
\mathbf{0 . 5 4 3}^{* *} \\
\end{array}$} & \multirow{2}{*}{$\begin{array}{l}\text { Comp. } \\
0.367^{* *}\end{array}$} & \multirow{2}{*}{$\begin{array}{l}\text { Meta. } \\
0.282^{*}\end{array}$} & \multirow{2}{*}{$\frac{\text { Affect }}{0.448^{* *}}$} & \multirow{2}{*}{\begin{tabular}{|c|} 
Social \\
$0.410^{* * *}$
\end{tabular}} \\
\hline \multirow{3}{*}{ Memory } & $\rho$ (rho) & & & & & & \\
\hline & Sig. (2-tailed) & & 000 & 0.003 & 0.026 & 000 & 0.001 \\
\hline & $\mathrm{N}$ & 65 & 65 & 65 & 65 & 65 & 65 \\
\hline \multirow{3}{*}{ Cognitive } & $\rho$ (rho) & $0.543^{* *}$ & 1.000 & $0.335^{* *}$ & $0.529^{* *}$ & $0.520^{* * *}$ & $0.635^{* *}$ \\
\hline & Sig. (2-tailed) & 000 & & 0.008 & 000 & 000 & 000 \\
\hline & $\mathrm{N}$ & 65 & 65 & 65 & 65 & 65 & 65 \\
\hline \multirow{3}{*}{ Compensation } & $\rho$ (rho) & $0.367^{* *}$ & $0.335^{* *}$ & 1.000 & 0.164 & $0.330^{* *}$ & 0.227 \\
\hline & Sig. (2-tailed) & 0.003 & 0.008 & & 0.202 & 0.009 & 0.076 \\
\hline & $\mathrm{N}$ & 65 & 65 & 65 & 65 & 65 & 65 \\
\hline \multirow{3}{*}{ Metacognitive } & $\rho$ (rho) & $0.282^{*}$ & $0.529^{* * *}$ & 0.164 & 1.000 & $0.445^{* *}$ & $0.571^{* *}$ \\
\hline & Sig. (2-tailed) & 0.026 & 000 & 0.202 & & 000 & 000 \\
\hline & $\mathrm{N}$ & 65 & 65 & 65 & 65 & 65 & 65 \\
\hline \multirow{3}{*}{ Affective } & $\rho$ (rho) & $0.448^{* *}$ & $0.520^{* *}$ & $0.330^{* *}$ & $0.445^{* *}$ & 1.000 & $0.498^{* *}$ \\
\hline & Sig. (2-tailed) & 000 & 000 & 0.009 & 000 & & 000 \\
\hline & $\mathrm{N}$ & 65 & 65 & 65 & 65 & 65 & 65 \\
\hline \multirow{3}{*}{ Social } & $\rho$ (rho) & $0.410^{* *}$ & $0.635^{* *}$ & 0.227 & $0.571^{* *}$ & $0.498^{* *}$ & 1.000 \\
\hline & Sig. (2-tailed) & 0.001 & 000 & 0.076 & 000 & 000 & \\
\hline & $\mathrm{N}$ & 65 & 65 & 65 & 65 & 65 & 65 \\
\hline
\end{tabular}


Table 9. Pairs of strategies showing a positive relationship

\begin{tabular}{|c|c|c|}
\hline Strategy Pair & $\mathrm{r}$ (Correlation coefficient) & $\mathrm{p}$ \\
\hline Cognitive \& Memory & $\mathrm{r}=0.543$ & $\mathrm{p}=000$ \\
\hline Cognitive \& Metacognitive & $\mathrm{r}=0.529$ & $\mathrm{p}=000$ \\
\hline Cognitive \& Affective & $\mathrm{r}=0.520$ & $\mathrm{p}=000$ \\
\hline Cognitive \& Social & $\mathrm{r}=0.635$ & $\mathrm{p}=000$ \\
\hline Metacognitive \& Social & $\mathrm{r}=0.571$ & $\mathrm{p}=000$ \\
\hline
\end{tabular}

After conducting Spearman's Rho correlation test, which is used to measure the strength of association between two variables, many correlations, could be found which are statistically significant (Table 9). For example, it was found that cognitive strategies were correlated with social strategies $(r=0.635, p=000)$. This indicates that with the increase in the value of cognitive strategies, the scores for the social ones will also increase and the participants who assign the cognitive ones lower values will give less for the social strategies. In the present study, all the above-mentioned pairs of strategies show a positive relationship. Interestingly, cognitive strategies show a positive relationship with all subgroups of strategies except the compensation strategies with which it has a weak positive relationship $(r=0.335)$. Such a relationship also demonstrates the fact that all subgroups of strategies work with each other, as Oxford [24] indicated.

\subsection{Gender}

One of the research questions was concerned with the relationship between strategy use and gender. When grouped by gender, there were $38(58.5 \%)$ female students and $27(41.5 \%)$ male students.

Table 10. Population distribution by Gender

\begin{tabular}{|c|c|c|}
\hline & Frequency & Percentage \\
\hline Female $(\mathbf{F})$ & 38 & 58.5 \\
\hline Male $(\mathbf{M})$ & 27 & 41.5 \\
\hline Total & 65 & 100 \\
\hline
\end{tabular}

The majority of the research studies which have been conducted regarding the LLS use with regards to the gender have indicated that the female learners use strategies more frequently than the male learners for example [25]. The present research study also indicated that women, although without much significant difference, informed employing language learning strategies $(\mathrm{M}=$ 3.28) slightly more frequently than men $(M=3.22)$. Below is the table indicating the different types of strategies according to gender.

From Table 11, it is evident that the female students reported using LLSs more frequently than the male students except in case of compensation and social strategies. The male participants $(\mathrm{N}=26)$ reported using the language learning strategies $\mathrm{M}=3.22(\mathrm{SD}=.48)$. By comparison, the female participants $(\mathrm{N}=36)$ reported using the language learning strategies with slightly high average $\mathrm{M}=3.28(\mathrm{SD}=.49)$. To check if there exist any significant gender difference statistically in LLS use, an independent-samples t-test was performed to compare LLS usage in female and male participants of this study. The same is shown in Table 11. There was no significant difference in the overall SILL scores for male participants $(\mathrm{M}=3.22, \mathrm{SD}=.48)$ and female participants $(\mathrm{M}=3.28$, $\mathrm{SD}=.49)$ conditions; $\mathrm{t}(60)=-.47, \mathrm{p}=.63$. The same was true for all other categories of the LLS. Mean differences showed that female participants $(\mathrm{M}=3.28)$ made use of strategies slightly more frequently than male learners $(\mathrm{M}=$ 3.22). Female students reported using metacognitive $(\mathrm{M}=$ 3.65), cognitive $(M=3.28)$ and affective strategies $(M=$ 3.03) more often than male counterparts. Male participants preferred using social $(\mathrm{M}=3.65)$ and compensation strategies $(M=3.37)$. The memory strategies were reported being employed less frequently by both groups. (for females, $\mathrm{M}=2.87$ and males $\mathrm{M}=2.83$ ).

Tables 12 and 13 are shown with LLS, which have a difference in their average use when compared in terms of gender. The first table shows those learning strategies whose $\mathrm{M}>3$ for female participants and $\mathrm{M}<3$ for male participants. The second one indicates the learning strategies with $M>3$ for male participants and $M<3$ for female ones.

Table 11. Result of t-test according to Gender

\begin{tabular}{|c|c|c|c|c|c|c|c|c|}
\hline \multirow{2}{*}{ Types } & \multicolumn{3}{|c|}{ Females } & \multicolumn{5}{|c|}{ Males } \\
\hline & Mean & SD & Freq. & Mean & SD & Freq. & $\mathbf{t}$ & Sig. \\
\hline Memory & 2.87 & .59 & Medium & 2.83 & .57 & Medium & -.271 & .788 \\
\hline Cognitive & 3.28 & .59 & Medium & 3.18 & .61 & Medium & -.640 & .525 \\
\hline Compensation & 3.30 & .66 & Medium & 3.37 & .74 & Medium & .402 & .689 \\
\hline Metacognitive & 3.65 & .76 & High & 3.51 & .69 & High & -.716 & .477 \\
\hline Affective & 3.03 & .66 & Medium & 2.89 & .62 & Medium & -.817 & .417 \\
\hline Social & 3.60 & .63 & High & 3.65 & .76 & High & .316 & .753 \\
\hline Overall SILL & 3.28 & .48 & Medium & 3.22 & .48 & Medium & -.478 & .634 \\
\hline
\end{tabular}


Table 12. Female participants' $M>3$ and Male participants' $M<3$

\begin{tabular}{|l|l|c|c|c|c|}
\hline \multirow{2}{*}{ LLS } & \multirow{2}{*}{ Type } & \multicolumn{2}{|c|}{ Female } & \multicolumn{2}{|c|}{ Male } \\
\cline { 3 - 6 } & & M & SD & \multicolumn{1}{|c|}{ M } & SD \\
\hline I look for opportunities to read as much as possible in Spanish. & Metacognitive & 3.47 & 1.18 & 2.81 & 1.27 \\
\hline $\begin{array}{l}\text { I remember the new words or phrases by remembering their } \\
\text { location on the page, on the board, or on a street sign. }\end{array}$ & Memory & 3.25 & 1.36 & 2.73 & 1.54 \\
\hline I write notes, messages, letters, or reports in Spanish. & Cognitive & 3.25 & 1.34 & 2.42 & 1.36 \\
\hline I try not to translate word-for-word. & Cognitive & 3.22 & 1.42 & 2.69 & 1.29 \\
\hline I read for pleasure in Spanish. & Cognitive & 3.17 & 1.32 & 2.69 & 1.38 \\
\hline I read Spanish without looking up every new word. & Compensation & 3.00 & 1.37 & 2.69 & 1.29 \\
\hline I write down my feelings in a language-learning diary. & Affective & 2.64 & 1.64 & 1.96 & 1.18 \\
\hline
\end{tabular}

Table 13. Male participants' $M>3$ and Female participants' $M<3$

\begin{tabular}{|c|c|c|c|c|c|}
\hline \multirow{2}{*}{ LLS } & \multirow{2}{*}{ Type } & \multicolumn{4}{|c|}{ Female Male } \\
\hline & & M & SD & M & SD \\
\hline $\begin{array}{l}\text { I connect the sound of a Spanish word and an image or picture of } \\
\text { the word to help me remember the word. }\end{array}$ & Memory & 2.99 & 1.12 & 3.54 & 1.17 \\
\hline I make up new words if I do not know the right ones in Spanish. & Compensation & 2.94 & 1.35 & 3.15 & 1.19 \\
\hline $\begin{array}{l}\text { I talk to someone else about how I feel when I am learning } \\
\text { Spanish. }\end{array}$ & Affective & 2.81 & 1.43 & 3.04 & 1.28 \\
\hline I make summaries of information that I hear or read in Spanish. & Cognitive & 2.78 & 1.35 & 3.04 & 1.37 \\
\hline I give myself a reward or treat when I do well in Spanish. & Affective & 2.78 & 1.55 & 3.04 & 1.37 \\
\hline
\end{tabular}

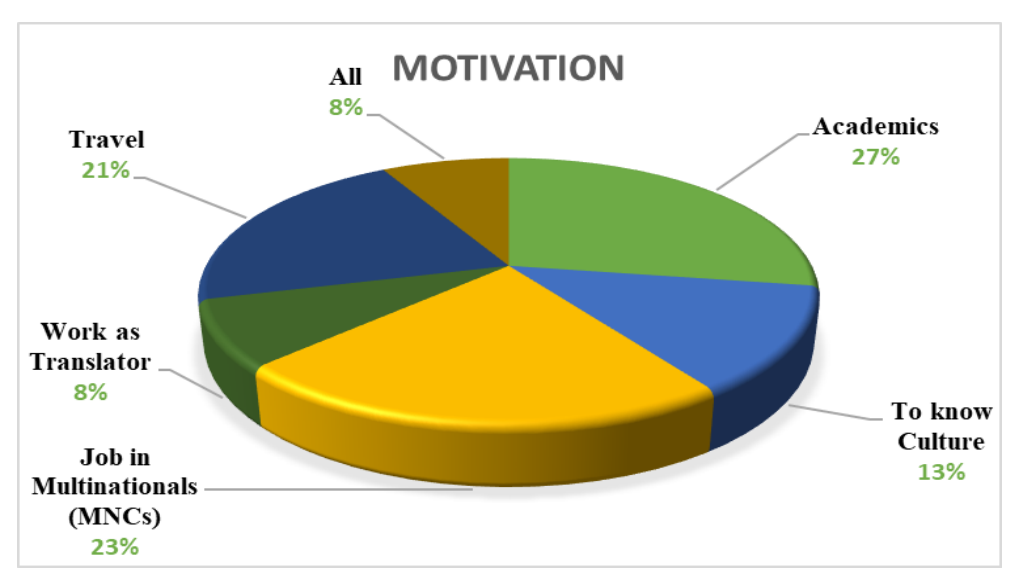

Figure 3. Different types of Motivation of participants

\subsection{Motivation}

The next research question dealt with looking at the types of motivation for learning Spanish and its relation to the usage of learning strategies. In order to know the reasons why the participants had to learn Spanish and, therefore, their motivation, they were asked the reason for learning Spanish. Below there is a graph showing the reasons (motivation) along with the percentage of participants.

According to $21 \%$ of students, the main motivation that drives them to learn Spanish as a foreign language is the need to get jobs in multinational companies. $27 \%$ of the students want to dedicate their careers to higher education and academic field and $13 \%$ of the students want to know the culture of Spanish-speaking countries. $21 \%$ of students want to learn the language to travel and $8 \%$ of students want to work as a translator or interpreter. The remaining $8 \%$ of the students responded positively with all the reasons that appeared in the survey. It was observed that most students want to learn this language to dedicate themselves to the academic field (27\%), followed by the learners who want to get a job in multinational companies $(23 \%)$ and those who need it for travelling (21\%).

Table 14 shows the distribution of students along with the mean of LLS use. The students have been divided into three categories depending on their reason for learning Spanish. The first category is intrinsic type, second extrinsic and the last is both who have responded with all the options. The participants did not give any other reason for learning Spanish though there was a space provided for that in the questionnaire. 
Table 14. Type of Motivation and LLS use

\begin{tabular}{|c|c|c|c|}
\hline Type of Motivation & Career option & \% of students & Mean \\
\hline \multirow{2}{*}{$\begin{array}{c}\text { Intrinsic Motivation } \\
(\mathbf{3 4 \% )}\end{array}$} & Knowing culture & 13 & 3.45 \\
\cline { 2 - 4 } & For travelling & 21 & 3.09 \\
\hline \multirow{2}{*}{$\begin{array}{c}\text { Extrinsic Motivation } \\
(\mathbf{5 8 \% )}\end{array}$} & Getting jobs in Multinationals (MNCs) & 23 & 3.39 \\
\cline { 2 - 4 } & Working as translator/Interpreter & 27 & 3.38 \\
\cline { 2 - 4 } & Academic career & 8 & 3.18 \\
\hline Intrinsic + Extrinsic (8\%)
\end{tabular}

Table 15. ANOVA Test to check statistically significant differences between the means of three groups

\begin{tabular}{|c|c|c|c|c|c|c|c|c|}
\hline \multirow[t]{2}{*}{ Categories } & \multicolumn{2}{|c|}{ Intrinsic } & \multicolumn{2}{|c|}{ Extrinsic } & \multicolumn{2}{|c|}{ Intr.+Extr. } & \multirow{2}{*}{$\mathbf{F}$} & \multirow{2}{*}{ Sig. } \\
\hline & Mean & SD & Mean & SD & Mean & SD & & \\
\hline Memory & 2.97 & .67 & 2.85 & .51 & 2.31 & .19 & 2.834 & .067 \\
\hline Cognitive & 3.22 & .63 & 3.24 & .61 & 3.27 & .31 & .014 & .986 \\
\hline Compensation & 3.42 & .77 & 3.29 & .65 & 3.16 & .66 & .392 & .678 \\
\hline Metacognitive & 3.22 & .56 & 3.77 & .66 & 3.88 & .64 & 4.561 & .014 \\
\hline Affective & 3.00 & .72 & 3.01 & .61 & 2.56 & .41 & 1.093 & .342 \\
\hline Social & 3.62 & .69 & 3.59 & .72 & 3.80 & .39 & .197 & .822 \\
\hline Overall Use & 3.23 & .56 & 3.29 & .46 & 3.18 & .26 & .183 & .833 \\
\hline
\end{tabular}

The extrinsically motivated students reported greater use of overall strategies $(\mathrm{M}=3.29, \mathrm{SD}=.46)$. ANOVA results revealed statistically significant differences $(\mathrm{F}=$ $4.561, \mathrm{p}=.014)$ in the use of metacognitive strategies by the participants of this study. There were no statistically significant differences $(\mathrm{F}=.183, \mathrm{SD}=.833)$ in the overall usage of the students. Table 15 presents the descriptive statistics of different categories of strategies' use according to the motivational orientations as reported by the students. The participants in the intrinsic group showed a medium frequency of use $(\mathrm{M}=3.23, \mathrm{SD}=.56)$, while the learners who reported both intrinsic and extrinsic orientation also reported a medium frequency of use $(\mathrm{M}=3.18, \mathrm{SD}=.26)$.

\section{Discussion on Research Questions}

The results of the present investigative research reveal many significant findings. The first and second research question of this investigative work dealt with trying to find out the most and least frequently used language-learning strategies used by the participants. The students reported using social strategies $(\mathrm{M}=3.62, \mathrm{SD}=.68)$ most frequently and memory strategies the least $(\mathrm{M}=2.85$, $\mathrm{SD}=.58)$. The metacognitive strategies were also found to be employed very frequently $(\mathrm{M}=3.60, \mathrm{SD}=.73)$ and were in the higher usage category. All other LLS categories were in the medium usage group. The overall strategy use was in the medium frequency range $(\mathrm{M}=3.27$, $\mathrm{SD}=.71)$. In general, the participants in the present study informed high to medium use of language learning strategies with a preference over social and metacognitive strategies. The result reflects that the students give great importance to the aspect of socializing while speaking Spanish as a foreign language. Almost the majority of the students who learn Spanish as a foreign language in India does not have the opportunity to experience the target language and culture. Hence, they start to practice and interact in the target language outside the classroom whenever they get the opportunity. They look for an opportunity to use their Spanish with their peers and people speaking Spanish. These results are in line with those of Phillips' [34] study of Asian ESL students who used social and metacognitive strategies more than affective and memory strategies. The findings also seem to be consistent with the other studies $[1,8,13,14,15,20$, 21]. The last three studies were carried out in Bangladesh and India. Khan [15] reported in his research study the same result with social and metacognitive strategies being the most used and affective and memory the least. Low use of memory strategies has been reported previously in many studies like $[13,2,44]$. The results of the study done by Park [29] reveal very similar results when compared with the results of this study.

Amongst the five most frequently used strategies, three were metacognitive strategies and one each from compensation and social. The three strategies which were 
reported to be least used and were in the low usage range pertained to memory and affective categories. The noting down of feelings (affective, $\mathrm{M}=2.35, \mathrm{SD}=1.49$ ), physically acting out new words (memory, $\mathrm{M}=2.0, \mathrm{SD}=$ 1.11) and using flashcards to remember (memory, $\mathrm{M}=$ $1.95, \mathrm{SD}=1.12$ ) are strategies which were not commonly used by the students.

The results in the current research showed that there were no statistically significant gender differences neither in overall use nor in any of the six categories. However, in terms of the mean of the usage of various categories, the female learners reported using more frequently the learning strategies except for social and compensation strategies where the male participants surpassed their female counterparts. The female ( $\mathrm{M}=3.28, \mathrm{SD}=.48)$ participants reported using a slightly higher frequency than male students $(\mathrm{M}=3.22, \mathrm{SD}=.48)$. The scores in the different categories indicate a positive attitude towards the use of LLS among the participants while learning Spanish as a foreign language. This result does not go with the general assumption as indicated earlier in this article. However, this study is in line with the previous studies like [11, 42, $36,18]$ in which similar results have been reported. For example, in Martínez et al. [18], there was no statistically significant difference in the usage of LLS gender-wise and in Radwan's [36] study, only social strategies were reported to have some statistical gender significance in the usage. The researcher has also presented two tables (Table $12 \& 13)$ with the strategy items, which have a mean difference in LLS usage for males and females.

The last question of the present research was related to the motivation type and its relation to LLS use. Fifty-eight per cent of the students reported learning Spanish for some kinds of utilitarian purpose, whereas thirty-four per cent informed learning it for either travelling or knowing target culture. Eight per cent of the students gave both types of motivational orientation. This is true in India context where the majority of the students want to start their career soon after finishing their undergraduate studies. After the liberalization of the Indian economy, the market provides good job opportunities for foreign language experts. Therefore, the majority of the students who come to university are looking for job opportunities soon after finishing their undergraduate studies. The participants with extrinsic orientation reported using the strategies more frequently than participants with intrinsic orientation. The result is not in line with the previous studies wherein there has been a significant effect of motivation on LLS usage $[20,43]$.

\section{Conclusions, Limitations and Future Area of Research}

The participants reported using language learning strategies with an average of 3.27 for the whole population, which is in the usage category of medium range. The participants reported using the social $(\mathrm{M}=3.2)$ and metacognitive strategies $(M=3.60)$ more frequently and memory strategies as the least frequently. There was no significant gender difference in LLS use. In the case of motivation, the students reported having extrinsic orientation the most. There is a need to further our understanding of the motivation by focusing primarily on this topic. The present study is a quantitative analysis of the student's response to their choice of leaning strategies and perhaps a qualitative analysis is needed to complement it and to get deeper insights to explain their choice and use of these particular strategies. This research study has established the basis for future research in the field of LLS for Spanish teaching and learning in the Indian context and perhaps more research is needed to profound our knowledge taking this study as a point of departure. This study has been limited to the students of two public universities and the field can be expanded by conducting studies in several other institutions both public and private and encompassing the teachers. This would help in getting a larger repertoire of strategies used by the students. Similar research can be carried out in different settings to determine the extent to which the findings could be generalized to other contexts. The present research focused on finding the language learning strategy use, profile of Indian students learning Spanish, their motivational orientations and examined the gender aspect in the usage of learning strategies. It was exploratory and one has to be cautious while generalizations of the result due to the small population size. A long-term longitudinal project could be set up and more students could be involved to investigate questions of strategy development over time and see their relationship with the motivation, proficiency and other individual variables.

There are many implications of the present study. The first one is the importance of integrating strategy training into the foreign language classroom. The result of this study could be used for the instructional purpose as well as curriculum design. The explicit and implicit strategy instructions into the regular lessons can be integrated by the teachers wherein the students should be made aware of the possibility of using a wide range of learning strategies according to task demand and contextual suitability.

\section{REFERENCES}

[1] Al-Buainain, H. (2010). Language learning strategies employed by English majors at Qatar University: Questions and queries. ASIATIC, Journal of English Language and Literature, 4(2), 92-120. Retrieved fromhttps://journals.iiu m.edu.my/asiatic/index.php/AJELL/article/view/525/492

[2] Alhaisoni, E. (2012). Language learning strategy use of Saudi EFL students in an intensive English learning context. 
Asian Social Science, 8(13), 115-127. doi: 10.5539/ass.v8n $13 \mathrm{p} 115$

[3] Cohen, A. D. (1998) Strategies in Learning and Using a Second Language. London and New York: Longman

[4] Dörnyei, Z. (1994). Understanding L2 motivation: On with the challenge. The Modern Language Journal. Vol. 78. No. $4,515-523$.

[5] Dornyei, Z. (2009). The Psychology of Second Language Acquisition. New York: Oxford University Press.

[6] Dreyer, C. and Oxford, R.L. (1996) Learning Strategies and Other Predictors of ESL Proficiency among Afrikaans Speakers in South Africa. In: Oxford, R.L., Ed., Language Learning Strategies around the World: Cross-Cultural Perspectives, University of Hawaii, Second Language Teaching \& Curriculum Center, Honolulu, 61-74.

[7] Ehrman, M.E. \& Oxford, R.L. (1989). Effects of sex differences, career choice, and psychological type on adults' language learning strategies. Modern Language Journal, 73(1), 1-13.

[8] Feleciya, A. and Meenakshi, K. (2016). English Language Learning Strategies used by Female ESL Learners of Vellore district-An Empirical Study. Indian Journal of Science and Technology, 9(39), https://www.doi.org/10.17 485/ijst/2016/v9i39/98843

[9] Gardner, R. C., \& Lambert, W. E. (1972). Attitudes and Motivation in Second Language Learning. Rowley, Massachusetts: Newbury House Publishers.

[10] Griffiths, C. (2003). Language Learning Stratety Use and Proficiency. $\mathrm{PhD}$ dissertation, University of Auckland. http://hdl.handle.net/2292/9

[11] Hashim, R. A., \& Azizah, S. (1994). Examining Learners' Language Learning Strategies. RELC Journal, 25(2), 1-20. https://doi.org/10.1177/003368829402500201

[12] Hsiao, T. \& Oxford, R.L. (2002). Comparing theories of language learning strategies: A confirmatory factor analysis. Modern Language Journal, 86(3), 368-383.

[13] Hong-Nam, K., \& Leavell, A. (2006). Language learning strategy use of ESL students in an intensive English learning context. System, 34(3), 399-415. doi: 10.1016/j.sy stem.2006.02.002

[14] Kavasoglu, M. (2009). Learning strategy use of pre-service teachers of English language at Mersin University. Procedia Social and Behavioral Sciences, 1(1), 993-997. doi: 10.1016/j.sbspro.2009.01.177

[15] Khan, M.F.R. (2012). Language Learning Strategies: A Study of Teacher and Learner Perceptions. BUP JOURNAL, 1(1), 140-153

[16] Larsen-Freeman, D. \& Long, M. H. (1991). An introduction to second language acquisition research. London \& NY: Longman

[17] Liao, Y. (2000). A study of Taiwanese junior high school students' EFL learning motivation and learning strategies. Unpublished master's thesis, National Changhua University of Education, Changhua, Taiwan.

[18] Martínez, J.J.R., M.L.V. Pérez; J.H. Navarrete (2016).
"Language learning strategy use by Spanish EFL students: the effect of proficiency level, gender, and motivation". Revista de Investigación Educativa,34(1), 133-149, https:// doi.org/10.6018/rie.34.1.232981

[19] Mochizuki, A. (1999). Language Learning Strategies Used By Japanese University Students. RELC Journal, 30(2), 101-113. https://doi.org/10.1177/003368829903000206

[20] Nikoopour, J., Salimian, S., Salimian, S., \& Farsani, M. A. (2012). Motivation and the choice of language learning strategies. Journal of Language Teaching and Research, 3(6), 1277-1283. doi:10.4304/jltr.3.6.1277-1283

[21] Nikoopour, J., Amini Farsani, M., \& Kashefi Neishabouri, J. (2011). Language learning strategy preferences of Iranian EFL learners. Proceedings of International Conference of Social Science and Humanity, Singapore, ICSSH, 5(2), 360-364. Retrieved from http:// www.ipedr.com/vol5/no2/ 78-H10203.pdf

[22] Nyikos, M. \& Oxford, R. (1993). A factor analytic study of language learning strategy use: Interpretations from information processing theory and social psychology. Modern Language Journal, 77(1), 11-22.

[23] O’Malley, J. and A.Chamot (1990). Language learning strategies. Cambridge: Cambridge University Press.

[24] Oxford, R. (1990). Language learning strategies: what every teacher should know. New York: Newbury House.

[25] Oxford, R. L. (1995). Gender differences in language learning styles: What do they mean? In J. M. Reid (ed.), Using learning styles in the ESL classroom (pp. 34-46). Boston: Heinle \& Heinle.

[26] Oxford, R. L. (2017). Teaching and researching language learning strategies. NY: Routledge. (Original book published in 2011)

[27] Oxford, R. L., \& Green, J. M. (1995). Making sense of learning strategy assessment: Toward a higher standard of research accuracy. TESOL Quarterly, 29(1), 166-171.

[28] Oxford, R. L., \& Nyikos, M. (1989). Variables affecting choice of language learning strategies by university students. Modern Language Journal, 73(3), 291-300.

[29] Park, G.P. (1997). Language learning strategies and English proficiency in Korean University. Foreign Language Annals 30 (2), 211-221.

[30] Patil, S. Karekatti, T. (2012). A Study of Language Learning Strategies Used by Engineering Students. English for Specific Purposes World 35(12), 1-18. Retrieved from http://www.esp-world.info/Articles_35/Sunanda_ESP_Wo rld.pdf

[31] Pawlak, M. (2019). Investigating language learning strategies: Prospects, pitfalls and challenges. Language Teaching Research. https://doi.org/10.1177/136216881987 6156

[32] Peacock, M. \& Ho, B. (2003). Student Language Learning Strategies across Eight Disciplines. International Journal of Applied Linguistics, 13(2), 179 - 200

[33] Peng, I. N. (2001). EFL motivation and strategy use among Taiwanese senior high school learners. Unpublished thesis, National Taiwan Normal University, Taipei, Taiwan. 
[34] Phillips, V. (1991). A look at learner strategy use and ESL proficiency. CATESOL Journal, 4(1), 57-67.

[35] Politzer, R.L. (1983). An exploratory study of self reported language learning behaviours and their relation to achievement. Studies in Second Language Acquisition 6, 54-65

[36] Radwan, A. A. (2011). Effects of L2 proficiency and gender on choice of language learning strategies by university students majoring in English. The Asian EFL Journal, 13(1), 114-162. Retrieved from http://www.asian-efl-journal.com /PDF/March-2011-aar.pd

[37] Rubin, J. (1975). What the "Good Language Learner" Can Teach Us. TESOL Quarterly, 9(1), 41-51.

[38] Rubin, J. (1981). Study of cognitive processes in second language learning, Applied Linguistics, 2(2), 117-131. https://doi.org/10.1093/applin/II.2.117

[39] Takeuchi, O. (2019) Language Learning Strategies: Insights from the Past and Directions for the Future. In: Gao X. (eds) Second Handbook of English Language Teaching. Springer International Handbooks of Education. Springer, Cham

[40] Takeuchi, O., Griffiths, C., \& Coyle, D. (2007). Applying strategies to contexts: the role of individual, situational, and group differences. In A. D. Cohen (ed.), Language Learning Strategies: Thirty Years of Research and Practice. (pp. 69-92). Oxford: Oxford University Press.

[41] Vaus, D.A. (1995). Surveys in Social Research. Sydney: Allen \& Unwin

[42] Wharton, G. (2000). Language Learning Strategy Use of Bilingual Foreign Language Learners in Singapore. Language learning, 50 (2), 203-243

[43] Xu, X. (2011). The relationship between language learning motivation and the choice of language learning strategies among Chinese graduates. International Journal of English Linguistics, 1(2), 203-212. doi:10.5539/ijel.v1n2p203

[44] Yang, M.N. (2007). Language learning strategies for college students in Taiwan: Investigating ethnicity and proficiency. The Asian EFL Journal, 9(2), 35-57. Retrieved from http://www.asian-efl-journal.com/June_2007_EBook_editi ons.pdf\#page $=35$ 